\title{
The notion of citizenship for people with intellectual disabilities in the UK: A life of their own
}

\author{
Julie A Lawrence ${ }^{1}$ and Linzi Brook ${ }^{2}$
}

\begin{abstract}
In this paper important issues, which involved vulnerable adults with Intellectual disabilities in transition from one rural location to another urban location, in England (UK) during 2014 are discussed. The notion of citizenship is discussed in relation to service users who had intellectual disabilities. This was originally embedded within the policy document Valuing People (DH, 2001). The use of a Total Communication approach by a Social Worker is also discussed, underpinned by the Human Rights framework and tenets of the Mental Capacity Act 2005. The outcomes from the transition process are highlighted, alongside the necessity to ensure that vulnerable adults are protected from abusive situations whilst living out their lives.
\end{abstract}

Keywords: disabilities; transition; social work; mental capacity; total communication; human rights

1. Lecturer In Social Work, University of Salford

2. User Development Worker (Learning Disabilities)

Address for Correspondence: University of Salford: j.lawrence@salford.ac.uk 


\section{Introduction}

This article explores key issues of importance involved when enabling people with complex health, social care and communication needs (intellectual disabilities) to move from one place of residence to another. The initiative was driven by a local authority intellectual disability service based in the UK. All the individuals were of white British origin and their ordinary area of residence was the geographical boundary of the local authority. The intention was to move seven adults (service users) from a rural residential care setting in Wales back to their local area in the UK. The residential establishment in Wales had been their 'home' for the past 30 years, but it was under risk of closure by the Care and Social Services Inspectorate (Wales).

Informed consent had been sought (where appropriate) and pseudonyms had replaced any identifying features about all the individuals in this article. In the spirit of confidentiality, names from the participating organisations have also remained anonymous.

Increasingly, people with intellectual disabilities are being helped to achieve ownership or secured tenancies of properties, so that their housing is relatively secure and is more in their control. Unlike residential care, in which housing and care are provided in a single package, in supported living, whatever care people require it is provided separately from their housing (Williams, 2009). Residential care homes available to people with intellectual disabilities often have real difficulties in enabling people who live in them to exert any real control over their 'home'. The main reason for this is that a residential home is fundamentally a work place for staff that supports individuals collectively. Duffy (2006) argues that people who are placed in a residential home may not have chosen to live with other residents, and living together can be difficult.

The remit of this project was to ascertain what the service users wanted, in terms of a change in living circumstances. This could have meant either staying in Wales or a return to their home town, in the UK. It was also important to ensure that all the service users were involved in their own transition, and to locate them at the heart of decision making during this process. The rationale was based upon the view that all the service users should receive the support to make choices and live lives they value. How this was achieved and some of the difficulties in trying to achieve this outcome are the main focus of this article.

Two aspects in particular were addressed. The first aspect was the use of Total Communication and the philosophy which lies behind it. Hansen's (1980) definition of Total Communication embraces a philosophical approach to communication and the needs of human beings to be able to connect with each other:

- Total Communication is a communication philosophy - not a communication method and not at all a teaching method. Total Communication is an approach 
to create a successful and equal communication between human beings with different language perception and/or production. To use Total Communication amounts to a willingness to use all available means in order to understand and be understood. (Hansen, 1980 p. 8)

This approach had been embraced by a Social Worker whose remit as a Development Worker was to initiate engagement, primarily with each service user. All the service users needed to understand why changes were necessary. This approach, in effect, facilitated 'vulnerable voices' to be heard through the efforts of effective communication techniques. These included the use of both verbal and non-verbal approaches, supplemented by objects of reference such as ornaments of significance, pictures, items of clothing and pieces of jewellery. The purpose was to inform other multi-disciplinary team colleagues, family members and key personnel about individual needs and wishes.

- The second aspect for consideration was the framework for the Human Rights Act 1998 (HRA) and how such a human rights approach could enhance professional practice. In essence, how would it be used in association with the Total Communication approach. Brayne and Carr (2013) argue that the overall HRA framework is relevant to Social Workers and their practice, but in this instance the focus was one legal Article in particular, namely, Article 8: The right to respect for private and family life, home and correspondence.

\section{Respecting adult service users: voices and choices}

All the service users ( $\mathrm{n}=7$ ) had unique and individual styles of both verbal and non-verbal communication needs. Four adults did not use words to speak, as illustrated in Table 1. All the service users had been known to the local authority intellectual disability service before they moved to Wales. The instigation for the change of location was due to the prevalence of safeguarding referrals, in relation to the residential home itself rather than referrals about individuals living there. The professionals involved, (Social Worker and Community Nurse) initiated the possibility of all service users moving back to their local town, embracing the concept of local citizenship, supported by appropriate accommodation and life-style choices. 
Table 1

Adults with an Intellectual Disability

\begin{tabular}{|c|c|c|c|}
\hline Age & Pseudonym & Intellectual disability & Communication needs \\
\hline $60 s$ & Carol & Yes & $\begin{array}{l}\text { Non-verbal. Interested in sign- } \\
\text { along and echoed some signs but } \\
\text { made none spontaneously. }\end{array}$ \\
\hline $50 \mathrm{~s}$ & John & Yes & $\begin{array}{l}\text { Good receptive verbal language. } \\
\text { Non-verbal for expression. Use of } \\
\text { body language. }\end{array}$ \\
\hline $50 \mathrm{~s}$ & Mike & $\begin{array}{l}\text { Yes } \\
\text { Visual Impairment }\end{array}$ & Good receptive language. \\
\hline $50 \mathrm{~s}$ & Lorraine & $\begin{array}{l}\text { Yes } \\
\text { Visual Impairment } \\
\text { Wheelchair user }\end{array}$ & $\begin{array}{l}\text { Non- verbal. } \\
\text { Use of body to accept/reject a } \\
\text { choice. }\end{array}$ \\
\hline $50 \mathrm{~s}$ & Peter & $\begin{array}{l}\text { Yes } \\
\text { Possible Autistic } \\
\text { Spectrum }\end{array}$ & $\begin{array}{l}\text { Non -verbal. } \\
\text { Use of objects to enjoy sensory } \\
\text { experiences. }\end{array}$ \\
\hline $40 \mathrm{~s}$ & Chris & Yes & $\begin{array}{l}\text { Non-verbal. } \\
\text { Use of body to accept/reject a } \\
\text { choice. }\end{array}$ \\
\hline $40 s$ & Carl & $\begin{array}{l}\text { Yes } \\
\text { Autistic Spectrum }\end{array}$ & $\begin{array}{l}\text { Verbal /used repetitive language. } \\
\text { Photos of important people/things. }\end{array}$ \\
\hline
\end{tabular}

Originally the service users had been placed 'out of county' (30 years ago) due to the lack of resources to accommodate them within the local authority boundary. Since that time the local authority adopted a strategy concerning local citizenship (Local Authority, 2001). This meant that local people who had intellectual disabilities should be given the opportunity to remain in the area in which they were born, and services planned to meet their needs in an appropriate way. The perspective from the local authority is based on the following principles:

- $\quad$ Being respected - being able to hold your head up high and getting respect from those around you 
- Being equal - citizens all have the same fundamental worth or dignity, they don't believe that just because someone has more money, power or a better-paid job this makes them a better person

- Being different - citizens are not identical, they have many different gifts which they bring together to build a better world. (Duffy, 2006)

Before 2001 money was disappearing outside the locality. Consequently, the authority has been committed to developing the right local services to make sure that people who are out of county can move back into their locality should they wish to do so.

One senior manager commented:

You need to be very person centred about what peoples' needs are. You also need to promote independence instead of dependence on services. Years ago people said that you needed a Social Worker to move house. This I found a curious concept, as this is not ordinary. (Senior Manager, Commissioning)

More recently, the local authority's publication Getting a Life, (2012-2015) made a number of value statements which reflected both the views of local citizens who had intellectual disabilities, and the direction of the service in the future. The following principle had a particular resonance with this project:

We want to make sure that people are the most important part of the future and that we work in real partnership with people about decisions being made, not just asking them what they think when decisions are made. (Getting a Life, p.6)

All the service users moved to their area of origin within a period of 12 months (2013-2014). The notion of local citizenship for adults who have intellectual disabilities was embedded within the policy document Valuing People (DH, 2001). The policy intended to transform the way people who have intellectual disabilities are supported in England. Burton (2004) asserts that the vision is based on legal and civil rights, independence and inclusion, and therefore provides a policy context for the enhancement of individuals' inclusion in community and society. However, in terms of individuals with intellectual disabilities, Redley and Weinberg (2007) emphasise the fact that it is very difficult to achieve these precepts as a large number of people with intellectual disabilities live within a context of life-long dependency and vulnerability. In legal terms, they are no longer subjected to the decision of others (Department for Constitutional Affairs, 2005) but are deemed able to make decisions for themselves, with support in some cases. Redley and Weinberg (2007) further state the importance of enhancing independence through the concepts of person-centred planning and direct payments.

However, this approach raised issues about this group of individuals in particular, 
given the fact that all the service users had complex communication needs. For example, securing initial engagement proved challenging alongside the values of inclusion and informed choice.

One difficulty encountered was the reluctance of staff already employed within the care home to engage with the work initiated by the Development Worker. The main reason for this was linked to the likely outcome that the home would be closed by the Care and Social Services Inspectorate. As a consequence of this, the service users' needs were more difficult to assess accurately and albeit within a limited time scale. This factor was potentially detrimental to each of the service users who were entitled to share their wishes and views, and not least be encouraged to participate during the process of change.

Due to the fact that the local authority embraced the tenets of the policy initiatives Valuing People (2001) and Valuing People Now, (DH, 2009), it was also deemed appropriate to offer support to all the individuals from a Development Worker who had knowledge, skills and techniques within the sphere of Total Communication. In addition to this, it was imperative that crucial resources in terms of time and commitment had been granted by the organisation as it was a pre-requisite to the potential long-term success for all concerned.

There was also a necessity to adhere to the principles of the Mental Capacity Act (MCA) 2005. The MCA enshrines several principles about capacity over which a consensus has developed in western societies (Berghmans et al., 2004). First the law seeks to counter the traditional discrimination against people who have cognitive limitations by creating a legal presumption in favour of capacity. Second, if properly implemented this principle could increase the autonomy of people with intellectual disabilities, which has been a major policy objective of Valuing People in particular (DH, 2001). These factors related to all the service users in terms of establishing their capacity to make important decisions. Or, at the very least, if some of the individuals who were identified as not having capacity, they could make a specific choice. Their views and feelings were also central to decisions being made on their behalf. This aspect was regarded as a vital component in order to maintain wellbeing for all the service users throughout the transitional stages. The promotion of wellbeing is the underlying principle of the Care Act 2014 and applies in all cases where a local authority is carrying out a care and support function, or making a decision, in relation to a person. The definition of wellbeing is a broad concept, and the statutory guidance definition goes some way to mirror the concepts of citizenship. Notable examples include protection from abuse and neglect, individual control over care and support and the way in which it is provided, and, not least, the suitability of living accommodation (The National Skills Academy: Social Care, 2014). 


\section{Total Communication: A humanistic approach to reciprocal communication}

The approach supported service users to express their views about whether they were happy living in their current situation. If not, why was this the case? All the individuals needed to understand that their circumstances would change, and more specifically, that a range of options was available. This included living in the area but not in the same care home, or remaining in the same location with improved conditions. The Development Worker employed a range of Total Communication techniques which encompassed a person centred planning (PCP) ethos. PCP is a set of approaches designed to assist someone to plan their life and support systems. It embraces the social model of disability and is used most often to enable individuals with disabilities or otherwise, to increase their personal self-determination and improve their own independence (Sanderson et al., 2006). This meant engagement on a one-to-one basis, to encapsulate personalities and in particular, communication styles and preferences, as illustrated in Table 1. Although all the service users had lived within the establishment for 30 years, there was very little information from the care providers about any specific communication techniques employed. This raised another question: how then had a person's needs and wishes been fulfilled over a period of 30 years? It would have been reasonable to expect a wealth of information to be available from the care home; given the fact staff had been supporting the service users for many years. Alternatively, this predicament was viewed by the local authority staff as an advantage to a certain extent, as any previous assumptions, misconceptions and prejudices were not transferred into new assessment documentation produced.

An initial visit by the Development Worker was arranged in December 2013 to meet all the service users and relevant care staff. The main focus of the visit was to introduce the idea of moving to another establishment in a different locality. It was also the beginning of the journey in terms of getting to know individuals and how they wished to live their lives. This was established through linking individuals to people they knew, places of importance and any known connections, across Wales. Conceptual analysis such as this enabled the individuals to be better understood and it created a 'visualisation map' about individuals and their lifestyles (see Figure 1). It also identified gaps and the lack of opportunities in peoples' lives. The approach helped to identify ways in which opportunities could then enhance personal experiences.

Each person was regarded as unique and 'what mattered' to him or her would encourage positive fulfilment, although there was an acknowledgement that the presence of an intellectual disability could influence and impact upon a chosen lifestyle. The identified new care providers (supported living model), also visited all the service users and arranged introductory visits to their potential new homes, to enable all the individuals to get a feel for the places available, and to meet potential new tenants already living in the accommodation. 


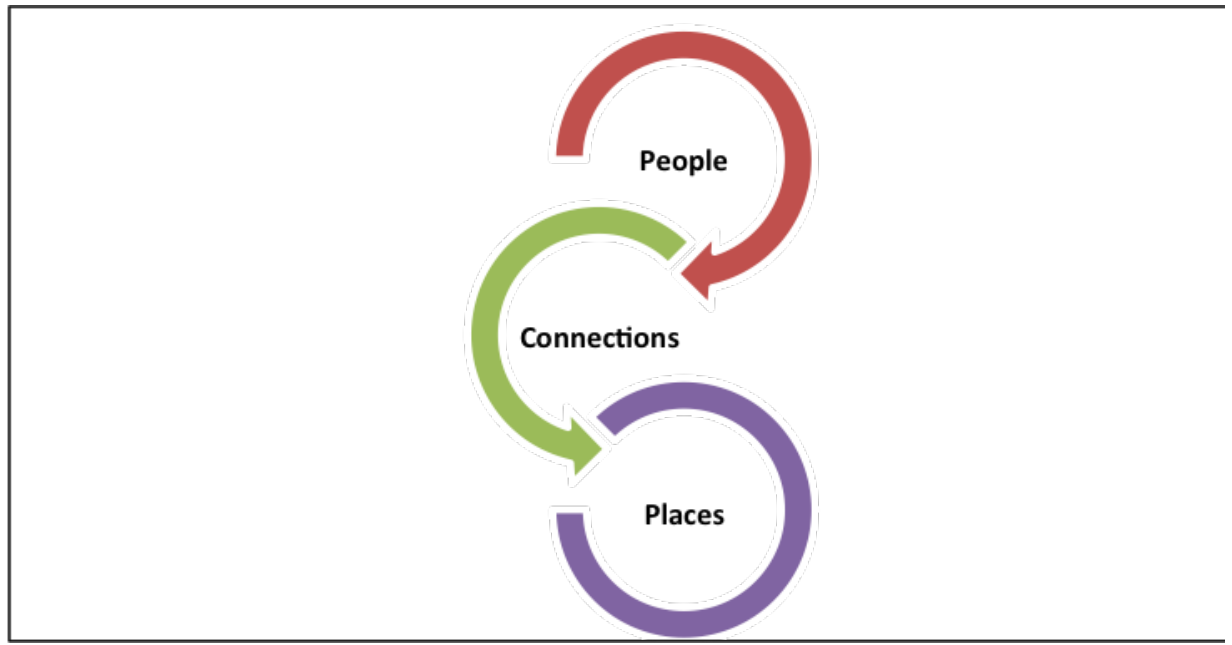

Figure 1 Visualisation Map

The map illustrates how the components linked together. Individual profiles about each person were developed using this approach.

\section{Case Example: Carl, 40 s}

Carl created a portfolio of things that he valued as important in his life. He did this through the use of a disposable camera to photograph important people, connections and places. He also used existing photographs and objects to share his thoughts with others. He spoke verbally about certain activities and people he valued most. What became evident from this was that he had a number of valued relationships in his life, but most involved paid staff. He also valued connections and some relationships with people from his home town and said he wanted the opportunity to develop them further. He spoke of one important relationship with another resident. The Development Worker worked in liaison with other professionals who were involved in his transition, to ensure that his support plan reflected the importance of this relationship and how it could be maintained in the future.

In terms of places, Carl mentioned two local areas which were of personal significance. Visiting the beach and enjoying long walks. He used to attend a local community centre, but he was stopped from attending because of the way in which he showed pleasure - clapping his hands. This was deemed inappropriate. The walks included solitude and this was the primary factor in his enjoyment. The challenge was accessibility of this activity within the (urban) environment, as he had chosen to return to his home town. Another important factor to emerge from the visualisation map was his desire to join in with local community groups - especially where enthusiasm and self-expression were valued and indeed encouraged. The new 
care provider was able to scope local opportunities prior to Carl's move so that he had a range of opportunities to access, in line with his preferences. This resulted in a positive transition and any anxieties about the 'unknown' had been alleviated, due to skilful interactions between the service user, Development Worker and his Social Worker.

\section{Case Example: Carol, 60s older woman}

Carol and the Development Worker spent some time together, during the first initial visit. The residential home staff did not provide any information about the way in which Carol communicated, although it was acknowledged that she did not use verbal language to express her needs and wishes. As such, sign-along was utilised as a way in which to communicate with her. Carol responded by echoing the signs and did so twice. She signed for 'yes' and 'good'. This was in relation to questions about whether she would be willing to move to another location 'yes' and enquiries made about the state of her health, which she signed 'good'. She also had an expressive face, smiled and clapped her hands to say 'yes'. She pushed objects away from her and looked away from the person attempting to communicate with her, to say 'no'.

Carol was shown images about houses (potential new homes) and places (Wales and the urban town) although in this instance she was unresponsive to all pictures. Due to the fact that Carol did not have any items which she identified as important to her, the Development Worker used her own 'box of importance' to try and initiate communication at an object level instead. Carol did however, use a disposable camera and had taken photographs of some of her most precious possessions, but no connections in terms of people or places.

Total Communication, underpinned by the notion of citizenship, resulted in each service user being involved in, and having some control over decisions about, their own futures. The degree of involvement varied for each individual due to the complexities of communication techniques. The approach encompassed the individual's right to know that an important change was imminent in their lives. This was something that the existing care home staff was reluctant to share with all the service users. The reasons given were primarily about individuals who might have displayed behaviours which 'challenged' the service and therefore the subject was best avoided. In addition to this, most of the care home staff were emotionally involved with each of the service users and therefore unable to provide a rationalised response towards the impending move. This factor also hindered any potential areas for development both within the care home and individuals. The care staff did ask for advice and support in terms of working in a positive way, but as time revealed, the suggestions were not implemented. Some of the suggestions included, improvements about procedural issues and pro-active engagement with each of the service users.

The communication techniques used included verbal communication, sign 
language, symbols, photographs, objects of reference, facial expressions and nonverbal gestures. The approach ensured that no pre-judgement had been made about which methods would be most effective, at least at the beginning of the engagement during 2013. Once each individual's style of communication was identified, they were encouraged to express their views through their chosen preferences.

\section{The Human Rights Act 1998 (HRA) and Article 8}

This legislation (HRA) cuts across all areas of social work practice and was implemented in 2000 by the incoming Labour Government. It works in conjunction with the Equality Act 2010. The Equality Act provides a legal framework to protect individuals from discriminatory and unfair treatment (Brayne \& Carr, 2013). The primary purpose of the HRA is to ensure that public bodies uphold the human rights principles, and to enable individuals to take cases where their human rights have been breached through the UK courts (Brayne and Carr, 2013). As to whether significant progress has been made in relation to the 'rights' element of the Valuing People agenda, this is more difficult to identify. Arguably the most significant development in relation to the human rights of people with intellectual disabilities has been the publication of the Joint Committee on Human Rights report A Life like Any Other? (March, 2008). This report highlights some of the difficulties encountered by people with intellectual disabilities (mainly in public/private care) and indicates how human rights breaches were identified in almost every aspect of people's lives, this included access to services but also personal relationships and participation in the local community. The government response in May (2008), specifically accepted that it is often the most vulnerable members of society, such as people with intellectual disabilities, who most need the protection and promotion of their rights under the HRA (bild, 2014). Fyson and Kitson (2010) argue that fundamental change is needed in order to ensure that the human rights of people with intellectual disabilities are genuinely respected and actively promoted.

In terms of this project, there had been commitment towards embracing the tenets of the HRA framework and more specifically Article 8, so that individual rights could be maintained throughout the process. This was established through the Total Communication approach and comprehension of:

- A developed sense of what the personalisation and choice agenda means

- The susceptibility to neglect and abuse

- The reasonable adjustments which needed to be made to ensure capacity

- The maintenance of partnerships with individuals, family members and key professionals 
People with profound disabilities can experience violation of their rights by people and services which fail to provide adequate levels of support which enables them to lead an active life (Fyson \& Kitson, 2010). The importance of Article 8 is the right of each individual to carry on their lives privately, without government interference, and the right to choose their sexual identity and lifestyle. The concept of privacy also covers the right to develop 'personalities' which includes friendships and other relationships. It also embraces the right to participate in essential economic, social, cultural and recreational activities within a community. In this instance the local authority had a duty to ensure that the process of 'decision making' had been addressed. The rationale for this was the legitimate aim of moving seven vulnerable adults from one familiar rural location, to another unfamiliar urban location, within a relatively short time frame.

Professionals working alongside people who have intellectual disabilities require a heightened awareness to vulnerable adults (in this instance) and can improve their practice in many ways. Social work in particular has a shared ethical base in terms of concerns regarding protection from abuse and neglect for service users and also the protection of the public from harm. Bollard (2009) asserts that assessing capacity of people with intellectual disabilities to make decisions or how best to assist them to effectively make decisions for themselves is a challenging issue for all professionals. Griffiths (2005) argues that the obligation is on public authorities, Social Workers and health professionals employed by them to ensure that service user' human rights are respected in their day-to-day lives.

At the time of writing, (January, 2015), all the service users had successfully moved to their area of origin - their home town, in the UK. All but one service user had become tenants and lived in supported living arrangements. During the transitional phase, it was possible to communicate with all the service users, but this varied in terms of communication styles and preferences. This was due in the main to a dearth of information about appropriate communication styles from the care home. In addition, there were added time constraints which affected the project as a whole. The Development Worker's time frame was December 2012 to March 2014. Some of this time was allotted to staff to explore the principles, process and practice of the Total Communication approach. The reluctance of the care home staff to inform all the service users about the closure of the home, did impact upon the service users in particular. There was a prevailing attitude that the investigation by the Care and Social Services Inspectorate would 'blow over' and their practice would continue as normal. In reality, if a more positive attitude had been adopted, the service users could have been encouraged to make informed choices and plan their future lives, within a more conducive environment. Although it was understandable to a certain extent, given the fact the care home would close imminently and the staff would then be unemployed.

Each individual was given the opportunity to be heard in their own way. The use of a Total Communication approach embodied the principles of citizenship, in 
terms of all the service users becoming partners in the planning of their future lives. From a Human Right's perspective, the use of the visualisation map encouraged individuals to share information about important people, connections they had and places of significance, all of which facilitated a potential new life.

The notion of 'decision making' during the transitional process had been a difficult concept to achieve. This was due to a major factor which impinged upon the true sense of decision making at important life-stages. All the service users were unfamiliar about how to 'go about' making life-style choices, especially when first approached to participate in their own destinies. When adhering to the MCA the person making the decision must be able to understand the options and make an informed decision. As such, best interest meetings were set up by the appointed Social Worker in respect of Carol, Lorraine, Peter and Chris.

In conclusion, one of the most important factors which impinged upon the project's success was the viability of moving seven vulnerable adults back to their area of origin, within a time frame dictated by the Care and Social Services Inspectorate in Wales. If, however, there had been more significant investment (in services) by the local authority thirty years ago, this type of scenario would not have arisen in the first place, and local citizens could have maintained their lives within their own neighbourhood, should they have chosen to do so.

An important 'lesson to be learnt' was the extent to which the imminent closure of the home had affected all parties involved from different perspectives. This included professional colleagues from the local authority, who had the responsibility to work through complex legal requirements appertaining to both the MCA and the HRA. In addition to which, they also had to ensure that a group of vulnerable adults were central to the decision making process, throughout the transitional phases.

Finally, this endorses the importance about how people with intellectual disabilities are vulnerable to many forms of abuse, and in this instance the lack of formal knowledge about the service users had hindered progress to some extent. A primary source of their oppression had been the way in which support services had been provided and limited their lives. However, the professionals involved from the local authority ensured that the best outcomes were achieved for all. The service users were re-located to their local urban town and several of them had re-connected with family members. Indeed, after 30 years of living in relative isolation, they were now enjoying a life of their own.

\section{References}

Berghmans, R., Dickenson, D., and Ter Meulen, R. (2004). Mental capacity: in search of alternative perspectives. Health Care Analysis, 12, 251-263

Bollard, M. (2009). Promoting a human rights approach for people with learning disabilities 
in community practice Primary Health Care, 19, 9, 26-28

Brayne, H., and Carr, H. (2013). Law for Social Workers. Oxford: Oxford University Press British Institute of Learning Disabilities. (2014). Factsheet - Human Rights Act Retrieved 15 September 2014, from www.bild.org.uk

Burton, M. (2004). Decoding Valuing People. Paper presented at the UK Community Psychology Conference, Exeter

Care Act. (2014). London: HMSO

Department for Constitutional Affairs. (2005). Mental Capacity Act. London: HMSO

Department of Health. (2001). Valuing People:A new strategy for learning disability for the 21st century London: The Stationery Office

Department of Health. (2009). Valuing People Now: From progress to transformation. London: HMSO

Duffy, S. (2006). Keys to Citizenship: A guide to getting good support for people with learning difficulties. Birkenhead: Paradigm

Fyson, R., and Kitson, D. (2010). Human rights and social wrongs: Issues in safeguarding adults with learning disabilities. Practice: Social Work in Action, 22(5)

Griffith, R. (2005). Human rights and district nursing practice. British Journal of Community Nursing, 10, 2, 86-91

Hansen, B. (1980). Aspects of Deafness and Total Communication in Denmark. Copenhagen

Joint Committee on Human Rights. (2008). A Life Like Any Other? Human rights of adults with learning disabilities London: HMSO

Local Authority. (2001). Looking Forward to the Future: Commissioning Strategy

Local Authority (2012-2015) Getting a Life. Commissioning Strategy

Redley, M., and Weinberg, D. (2007). Learning disability and the limits of liberal citizenship: interactional impediments to political empowerment. Sociology of Health and Illness, 29, 5, 767-786

Sanderson, H., Thompson J, and Kilbrane J. (2006). The Emergence of Person Centred Planning as Evidence Based Practice Journal of Integrated Care, 14, 2

The National Skills Academy: Social Care. (2014). Care Act learning and development materials Retrieved 6 October 2014, from www.nsasocialcare.co.uk

Williams, P. (2009). Social Work with People with Learning Difficulties. Exeter: Learning Matters 